\title{
Self-Separating Homogeneous Copper (I) Catalysts
}

\author{
David E. Bergbreiter*, Patrick N. Hamilton, and Nirmal M. Koshti \\ Department of Chemistry, Texas A\&M University, P.O. Box 30012, College
}

Station, Texas 77842-3012, USA

bergbreiter@tamu.edu

\section{Supplementary Material Table of Contents}

Chemicals

S1

Synthesis of $N, N$-Bis(2-Pyridylmethyl)- $N$-Propargylamine $\quad \mathrm{S} 2$

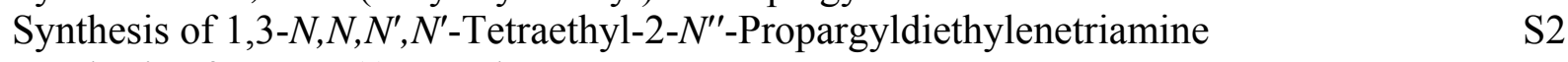

Synthesis of PIB-Cu(I) complex $4 \quad$ S2

Synthesis of PIB-Cu(I) complex $3 \quad$ S2

ATRP polymerization of styrene with $\mathbf{3}$

S3

Recycling of $\mathbf{3}$ in the ATRP polymerization of styrene

S3

ATRP polymerization of methyl methacrylate with $\mathbf{3}$

S3

Synthesis of PIB-Ligand 5

S4

General procedure for the ATRP polymerization of styrene with $\mathbf{3}$ and $\mathbf{5} \quad$ S4

Recycling of $\mathbf{3}$ and $\mathbf{5}$ in the ATRP polymerization of styrene

S4

General procedure for 'click' reactions

S4

References for Supplementary Materials

Chemicals. Styrene (sty, 99\%, Aldrich) was distilled, stored under nitrogen in a freezer, and passed through a column filled with basic alumina prior to use. $\mathrm{CuCl}$ (97\%, Alfa Aesar) and tin (II) 2-ethylhexanoate (95\%, Aldrich) were used as received. Propargyl amine $(98 \%$, Aldrich), 2-picolyl chloride hydrochloride (98\%, Aldrich), ethyl 2-bromoisobutyrate (98\%, Aldrich), 2-pyridinecarboxaldehyde and other solvents were used without further purification. Polyisobutylene (PIB) was obtained from BASF (Glissopal 1000 or 2300). ${ }^{1} \mathrm{H}$ NMR spectra were obtained on Varian Inova 300 or Mercury 300 spectrometers at $300 \mathrm{MHz}$ and reported in ppm referenced to $\mathrm{CDCl}_{3} .{ }^{13} \mathrm{C}$ NMR spectra were obtained on Varian Inova 300 or Mercury 300 spectrometers at $75 \mathrm{MHz}$ and reported in ppm referenced to the chloroform contaminant in $\mathrm{CDCl}_{3}$ unless otherwise stated. Gel permeation chromatography was performed using a Viscotek triple detector system using a GMHx1 column set with tetrahydrofuran as the eluting solvent. A flow rate of $1 \mathrm{~mL} / \mathrm{min}$ was used and molecular weights and polydispersity were determined using polystyrene standards using the software supplied by Viscotek. 
Synthesis of $N, N$-Bis(2-Pyridylmethyl)- $N$-Propargylamine. Following a procedure used to prepare $N$-propyl- $N, N$-di(2-pyridylmethyl)amine, ${ }^{1}$ a sample of 2-picolyl chloride hydrochloride (2.06 g, $12.6 \mathrm{mmol})$ was dissolved in a methanol/water mixture $(20 \mathrm{~mL} / 10 \mathrm{~mL})$ in a pressure vessel and propargyl amine $(0.34 \mathrm{~g}, 6.2 \mathrm{mmol})$ was added. After briefly flushing with nitrogen, the reaction solution was sealed and heated at $65{ }^{\circ} \mathrm{C}$ for $12 \mathrm{~h}$. After removing the solvent under reduced pressure with a rotary evaporator, $10 \mathrm{~mL}$ of water was added and the aqueous phase was separated. The aqueous phase was extracted with $3 \times 40 \mathrm{~mL}$ of dichloromethane. The organic phases were combined and washed once with $20 \mathrm{~mL}$ of $3 \mathrm{M} \mathrm{NaOH}$ and then dried over $\mathrm{MgSO}_{4}$. After filtering, $100 \mathrm{~mL}$ of anhydrous diethyl ether was added and the resulting mixture was filtered. Removal of the solvent under reduced pressure using a rotary evaporator yielded $1.17 \mathrm{~g}$ (79.5\% yield) of the desired alkyne product that was used directly in a Fokin-Huisgen cyclization with a PIB-bound azide. ${ }^{1} \mathrm{H}$ NMR $\left(\mathrm{CDCl}_{3}\right): \delta 2.33(\mathrm{t}, J=2.4 \mathrm{~Hz}, 1 \mathrm{H}), 3.46(\mathrm{~d}, J=$ $2.4 \mathrm{~Hz}, 2 \mathrm{H}), 3.95(\mathrm{~s}, 4 \mathrm{H}), 7.20(\mathrm{~m}, 2 \mathrm{H}), 7.55(\mathrm{~m}, 2 \mathrm{H}), 7.69(\mathrm{~m}, 2 \mathrm{H}), 8.60(\mathrm{~m}, 2 \mathrm{H}) .{ }^{13} \mathrm{C} \mathrm{NMR}$ $\left(\mathrm{CDCl}_{3}\right): \delta 42.5,59.4,67.9,73.6,122.1,123.1,136.5,149.2,158.7$.

Synthesis of 1,3- $N, N, N^{\prime}, N^{\prime}$-Tetraethyl-2- $N^{\prime \prime}$-Propargyldiethylenetriamine. A mixture of $N, N, N^{\prime}, N^{\prime}$-tetraethyldiethylenetriamine $(1.07 \mathrm{~g}, 4.99 \mathrm{mmol})$, propargyl chloride $(0.372 \mathrm{~g}, 4.99$ $\mathrm{mmol})$, potassium iodide $(10 \mathrm{mg}, 0.06 \mathrm{mmol})$ and cesium carbonate $(1.625 \mathrm{~g}, 4.98 \mathrm{mmol})$ in acetonitrile $(15 \mathrm{~mL})$ was stirred at room temperature for $72 \mathrm{~h}$. The solids of the reaction mixture were filtered off. The solvent was then removed under reduced pressure using a rotary evaporator to produce a residue that was extracted with diethyl ether $(20 \mathrm{~mL})$. The diethyl ether was then removed under reduced pressure using a rotary evaporator to yield $1.02 \mathrm{~g}$ of the desired alkyne functionalized ligand ( $81 \%$ yield) as a pale yellow liquid that was used directly in a Fokin-Huisgen cyclization with a PIB-bound azide. ${ }^{1} \mathrm{H}$ NMR $\left(\mathrm{CDCl}_{3}\right): \delta 1.02(\mathrm{t}, J=6 \mathrm{~Hz}, 12 \mathrm{H})$, $2.19(\mathrm{t}, J=2.4 \mathrm{~Hz}, 1 \mathrm{H}), 2.57(\mathrm{~m}, 16 \mathrm{H}), 3.46(\mathrm{~d}, J=2.4 \mathrm{~Hz}, 2 \mathrm{H}) .{ }^{13} \mathrm{C} \mathrm{NMR}\left(\mathrm{CDCl}_{3}\right): \delta 11.7$, 42.9, 47.4, 51.0, 52.0, 73.0, 78.6.

Synthesis of PIB-Cu(I) complex 4. To a pressure vessel, polyisobutylene terminated azide ${ }^{16}$ $(1.02 \mathrm{~g}, 0.43 \mathrm{mmol})$ and $1,3-N, N, N^{\prime}, N^{\prime}$-tetraethyl-2- $N^{\prime \prime}$-propargyldiethylenetriamine $(0.22 \mathrm{~g}$, $0.86 \mathrm{mmol})$ were added to $20 \mathrm{~mL}$ of a heptane/ethanol $(1: 1 / \mathrm{v}: \mathrm{v})$ and $\mathrm{CuCl}(0.005 \mathrm{~g}, 0.04 \mathrm{mmol})$ mixture. Nitrogen was bubbled through the solution for $15 \mathrm{~min}$. The reaction was then sealed and heated at $80{ }^{\circ} \mathrm{C}$ for $16 \mathrm{~h}$. After cooling, water was added to produce a biphasic mixture. The heptane solution was then removed and an additional $100 \mathrm{~mL}$ of hexanes was added to the heptane solution. This heptane/hexanes solution was then washed with acetonitrile, DMF, diethylene glycol diacetate and methanol (1 x $50 \mathrm{~mL}$ each) respectively. This heptane/hexanes solution was then passed through a silica plug to remove any chelated copper. The solvent was then removed under reduced pressure using a rotary evaporator to give $0.91 \mathrm{~g}(81 \%$ yield) of 4 . ${ }^{1} \mathrm{H} \mathrm{NMR}\left(\mathrm{CDCl}_{3}\right): \delta$ 0.77-1.80 (br m, 347H), 2.57 (br m, 16H), 3.89 (s, 2H), 4.03 (dd, $J=8.8$ and $13.8 \mathrm{~Hz}, 1 \mathrm{H},), 4.23$ (dd, $J=6.1$ and $13.2 \mathrm{~Hz}, 1 \mathrm{H}), 7.46(\mathrm{~s}, 1 \mathrm{H})$.

Synthesis of PIB-Cu(I) complex 3. The PIB complex 3 was synthesized in a procedure similar to complex 4 using an equimolar quantity of $\mathrm{CuCl}$ and $N, N$-bis(2-pyridylmethyl)- $N$ propargylamine. The same workup was followed except for filtration through silica. The reaction yielded $0.75 \mathrm{~g}(71.5 \%$ yield $)$ of the desired complex 3 . ${ }^{1} \mathrm{H}$ NMR spectrum of compound compared to an analog (4) prepared with minimal amount of copper. IR analysis of $\mathbf{3}$ showed complete disappearance of both the PIB azide 
stretch $\left(2097 \mathrm{~cm}^{-1}\right)$ and the alkyne-functionalized ligands' stretch $\left(2120 \mathrm{~cm}^{-1}\right)$. Inductively coupled plasma mass spectroscopy (ICP-MS) indicated a metal loading of $0.115 \mathrm{mmol}$ copper/g of 3 .

ATRP polymerization of styrene with 3. $3(0 . .153 \mathrm{~g}, 0.058 \mathrm{mmol})$ was dissolved in $2 \mathrm{~mL}$ of heptane and placed in a $25 \mathrm{~mL}$ Schlenk tube along with styrene (4.5 g, $43 \mathrm{mmol})$. Nitrogen was then bubbled through this solution for 15 minutes, and a solution of tin (II) 2-ethylhexanoate ( $10.4 \mathrm{mg}, 0.03 \mathrm{mmol}$ ) in $0.3 \mathrm{~mL}$ of heptane was then added. The solution was then sealed by a rubber septum and nitrogen was bubbled through the reaction solution for $30 \mathrm{~min}$.. Previously degassed ethyl 2-bromoisobutyrate $(20 \mu \mathrm{L}, 0.13 \mathrm{mmol})$ was added via syringe and the reaction was immediately immersed in an oil bath that was preset to the specific reaction temperature $\left(110^{\circ} \mathrm{C}\right)$. After a set reaction time, the reactions were allowed to cool to room temperature and transferred to a $50 \mathrm{~mL}$ centrifuge tube. The mixture was then centrifuged at $1500 \mathrm{rpm}$ at $5{ }^{\circ} \mathrm{C}$ for $1 \mathrm{~h}$ to ensure complete separation of the product from the heptane phase. The resulting heptane phase was removed and $2 \mathrm{~mL}$ of fresh heptane was added to the product polystyrene phase to remove any residual catalyst. After removal of residual solvents under reduced pressure, a sample of polymer was analyzed for residual copper content by ICP-MS. The copper content of the product polystyrene was determined to be $23 \mathrm{ppm}$. Measured amounts of polystyrene were also redissolved in tetrahydrofuran, filtered through a PTFE filter $(0.45 \mu \mathrm{m})$, and analyzed by gel permeation chromatography (GPC). The product polystyrene had a $M_{\mathrm{n}}=$ 26,000 Da with a $M_{\mathrm{w}} / M_{\mathrm{n}}=1.34$.

Recycling of 3 in the ATRP polymerization of styrene. In a typical recycling experiment, all the heptane phases from a given cycle were combined and concentrated to yield a polyisobutylene copper residue which was then redissolved in heptane. This heptane solution was used as the catalyst solution in the next cycle. The results of these polymerizations can be seen in Table below.

\begin{tabular}{|c|c|c|c|c|}
\hline Cycle & $\%$ Yield $^{\mathrm{a}}$ & $\begin{array}{c}M_{\mathrm{n}} \\
(\text { calc) }\end{array}$ & $M_{\mathrm{n}}{ }^{\mathrm{c}}$ & $M_{\mathrm{w}} / M_{\mathrm{n}}{ }^{\mathrm{c}}$ \\
\hline 1 & 53.6 & 26000 & 18000 & 1.34 \\
\hline 2 & 55.1 & 22000 & 18000 & 1.26 \\
\hline 3 & 38.7 & 13000 & 17000 & 1.37 \\
\hline
\end{tabular}

ATRP polymerization of methyl methacrylate with 3. $3(0.143 \mathrm{~g}, 0.055 \mathrm{mmol})$ was dissolved in $2 \mathrm{~mL}$ of toluene and placed in a $25 \mathrm{~mL}$ Schlenk tube along with styrene (4.5 g, 45 mmol). The solution was then sealed by a rubber septum and nitrogen was bubbled through the reaction solution for $30 \mathrm{~min}$. Previously degassed ethyl 2-bromoisobutyrate ( $20 \mu \mathrm{L}, 0.13 \mathrm{mmol}$ ) was added via syringe and the reaction was immediately immersed in an oil bath that was preset to the specific reaction temperature $\left(60^{\circ} \mathrm{C}\right)$. After $24 \mathrm{~h}$, the reaction was allowed to cool to room. Due to the complete insolubility of the product poly(methyl methacrylate) in heptane, 1 $\mathrm{mL}$ of heptane was added to produce a biphasic reaction mixture. The mixture was then centrifuged at $1500 \mathrm{rpm}$ at $5{ }^{\circ} \mathrm{C}$ for $1 \mathrm{~h}$ to ensure complete separation of the product from the heptane phase. After removal of residual solvents under reduced 
pressure using a rotary evaporator, measured amounts of poly(methyl methacrylate) were redissolved in tetrahydrofuran, filtered through a PTFE filter $(0.45 \mu \mathrm{m})$, and analyzed by gel permeation chromatography (GPC). The product poly(methyl methacrylate) had a $M_{\mathrm{n}}=27,000$ Da with a $M_{\mathrm{w}} / M_{\mathrm{n}}=1.23$.

Synthesis of PIB-Ligand 5. Polyisobutylene terminated amine ${ }^{16}(1.05 \mathrm{~g}, 0.45 \mathrm{mmol})$ was dissolved in $50 \mathrm{~mL}$ toluene and 2-pydridine carboxaldehyde $(0.105 \mathrm{~g}, 0.98 \mathrm{mmol})$ was then added and the solution was stirred and heated at reflux with a Dean-Stark trap. After two hours, the reaction was allowed to cool and the solvent was removed under reduced pressure using a rotary evaporator. The resulting residue was then dissolved in $100 \mathrm{~mL}$ of hexanes and washed with 3 x $50 \mathrm{~mL}$ of $90 \%$ ethanol and dried over $3 \AA$ molecular sieves. After filtration, the solvent was removed under reduced pressure using a rotary evaporator to give $0.95 \mathrm{~g}$ (87\% yield) of 5 . ${ }^{1} \mathrm{H}$ NMR $\left(\mathrm{CDCl}_{3}\right): \delta$ 0.77-1.80 (br m, 335H), $3.38(\mathrm{dd}, \mathrm{J}=8.3$ and $13.4 \mathrm{~Hz}, 1 \mathrm{H}),, 3.66(\mathrm{dd}, \mathrm{J}=6.1$ and $13.4 \mathrm{~Hz}, 1 \mathrm{H}), 7.32(\mathrm{~m}, 1 \mathrm{H}), 7.75(\mathrm{~m}, 1 \mathrm{H}), 8.02(\mathrm{~m}, 1 \mathrm{H}), 8.36(\mathrm{~s}, 1 \mathrm{H}), 8.65(\mathrm{~m}, 1 \mathrm{H})$.

General procedure for the ATRP polymerization of styrene with 3 and 5 . $3(0.098 \mathrm{~g}$, $0.038 \mathrm{mmol})$ and $5(0.048 \mathrm{~g}, 0.020 \mathrm{mmol})$ were dissolved in $2 \mathrm{~mL}$ of heptane and placed in a 25 $\mathrm{mL}$ Schlenk tube along with styrene $(4.5 \mathrm{~g}, 43 \mathrm{mmol})$. Nitrogen was then bubbled through this solution for 15 minutes, and a solution of tin (II) 2-ethylhexanoate (10.4 mg, $0.03 \mathrm{mmol})$ in 0.3 $\mathrm{mL}$ of heptane was thenadded. The solution was then sealed by a rubber septum and the reaction solution degassed by 3 cycles of freeze/pump/thaw under vacuum to remove oxygen. Previously degassed ethyl 2-bromoisobutyrate $(20 \mu \mathrm{L}, 0.13 \mathrm{mmol})$ was added via syringe and the reaction was immediately immersed in an oil bath that was preset to the specific reaction temperature $\left(110^{\circ} \mathrm{C}\right)$. After a set reaction time, the reactions were allowed to cool to room temperature and transferred to a $50 \mathrm{~mL}$ centrifuge tube. The mixture was then centrifuged at $1500 \mathrm{rpm}$ at $5{ }^{\circ} \mathrm{C}$ for $1 \mathrm{~h}$ to ensure complete separation of the product from the heptane phase. The resulting heptane phase was removed and $2 \mathrm{~mL}$ of fresh heptane was added to the product polystyrene phase to remove any residual catalyst. After removal of residual solvents under reduced pressure, a sample of polymer was analyzed for residual copper content by ICP-MS. Measured amounts of polystyrene were also redissolved in tetrahydrofuran, filtered through a PTFE filter $(0.45 \mu \mathrm{m})$, and analyzed by gel permeation chromatography (GPC). The results of these polymerizations can be seen in Table 1 .

Recycling of 3 and 5 in the ATRP polymerization of styrene. In a typical recycling experiment, all the heptane phases from a given cycle were combined and concentrated to yield a polyisobutylene copper residue which was then redissolved in heptane. This heptane solution was used as the catalyst solution in the next cycle. The results of these polymerizations can be seen in Table 1.

General procedure for 'click' reactions. A mixture of poly $(N$-isopropyl acrylamide-coazidoethylacrylate) (13:1), (0.52 g, $0.32 \mathrm{mmol}$ of azide), phenyl acetylene $(0.066 \mathrm{~g}, 0.64 \mathrm{mmol})$ and $3(0.040 \mathrm{~g}, 5.0$ mole $\%)$ in $6 \mathrm{~mL}$ of a heptane:ethanol solvent mixture (2:1/vol:vol) was stirred under nitrogen at $80{ }^{\circ} \mathrm{C}$ for $24 \mathrm{~h}$. The reaction solution was then cooled and an additional $20 \mathrm{~mL}$ of a 
heptane:ethanol solvent mixture $(2: 1 / \mathrm{vol}: \mathrm{vol})$ was added. Then $1.2 \mathrm{~mL}$ of water was added to induce a biphasic separation. The resulting biphasic solution was centrifuged at $10{ }^{\circ} \mathrm{C}$ for 20 min. The PIB bound catalyst 4 was recovered from the upper heptane phase whereas the alcohol phase afforded the PNIPAM-bound triazole as a white solid. The PNIPAM-bound triazole was further purified by dissolution in water $\left(<30{ }^{\circ} \mathrm{C}\right)$ and precipitation by heating the aqueous polymer solution above $50{ }^{\circ} \mathrm{C}$. The precipitated PNIPAM-bound triazole was isolated and dried under vacuum. $(0.39 \mathrm{~g}, 70 \%)$. Analysis by IR showed complete absence of the starting azide stretch. ${ }^{1} \mathrm{H} \mathrm{NMR}\left(\mathrm{CDCl}_{3}\right)$ showed the presence of the triazole proton and the phenyl protons. LCST of the product was found to be lower $\left(27^{\circ} \mathrm{C}\right)$ compared to the LCST of the starting material $\left(31^{\circ} \mathrm{C}\right)$.

\section{References for Supplementary Materials}

1. Carney, M. J.; Robertson, N. J.; Halfen, J. A.; Zakharov, L. N.; Rheingold, A. L. Organometallics 2004, 23, 6184-6190. 